\title{
Osteopontin Measurement
}

National Cancer Institute

\section{Source}

National Cancer Institute. Osteopontin Measurement. NCI Thesaurus. Code C124349.

The determination of the amount of osteopontin present in a sample. 